\title{
Lifestyle: Bioethics at a Critical Juncture
}

\author{
IGNAAS DEVISCH and MYRIAM DEVEUGELE
}

More than ever, the way we live our lives has become subject to our own decisionmaking. Our whole way of living, in particular what we do to our body, has become the expression of personal lifestyle choices. Because we can make changes to our body according to our own individual preferences, every aspect of our life begins to be seen as the result of individual and voluntary decisions. The comparison with advertising is pertinent here: we should no longer accept the way we are but can choose from a variety of options. Go to any supermarket and look around: innumerable products are promoted because of their healthy ingredients, whether to lower our cholesterol or heighten our natural resistance. And, of course, we buy what is on offer.

Consequently, there are increasing discussions in healthcare and bioethics journals and forums about lifestyle and the autonomy of the individual. Lifestyle is at the center of current debate about how biotechnology or drugs can help people adjust their rapidly changing lifestyles. ${ }^{1}$ It is also an issue in debates on the ethics of current health policy and health insurance: private insurance companies are increasingly promoting the values of mass sports, fitness, and a healthy way of living.

In many countries, the pursuit of a healthy lifestyle has or is expected to become a criterion in the allocation of healthcare services. One of the crucial questions is what could be the consequences of this evolution for healthcare policy for individuals and for society in general? If we consider individuals as autonomous and regard the way they live as largely a matter of their own free choice, would it then not be "logical" to hold patients personally responsible for making (un)healthy lifestyle choices, when they try to obtain insurance or enter healthcare facilities? And if the individuals are unwilling to change their risky behavior, could they then also be denied healthcare services? In short, the discussion about lifestyle also concerns responsibility and the amount of control that others should be allowed to exercise over an individual's choice for a particular way of living. Critics of paternalism talk about control and tyranny, whereas defenders point out the importance of public interest. ${ }^{2}$

In this article, we will take a step back from current approaches to lifestyle and concentrate on the history of this concept. To do this, we use a method derived from the work of the French philosopher Michel Foucault, the genealogical method. ${ }^{3}$ A genealogical analysis aims to unravel the previous turns and shifts of meaning of the central concepts of a given system of thought in order to understand what is going on today.

\section{Current Discussion on Lifestyle: The Example of Obesity}

First, let us illustrate the importance of the above discussion by attending to a topical example, obesity. As lifestyle 
is often a crucial factor in the treatment of obese patients, it is more than likely that "lifestyle will be an issue" ${ }^{\text {"4 }}$ in current and future policy discussions about obesity. Ethical or political choices will have to be made, and some already simply speak about the need to "force them to diet." ${ }^{5}$ A crucial point in this discussion deals with the way we understand the concept of lifestyle: Is it fair to hold obese patients fully responsible for their condition because it is simply the result of their lifestyle choices?

Although at first glance the choices seem simple and unambiguous, the reality behind them is complex. Food and physical activity are more than aspects of our health. They are an integral part of our sense of well-being as persons, individually as well as socially, and therefore cover many important values of our lives that are related to our food patterns, social behavior, and aspects of socialization. It is common sense to believe that food choices are strictly personal, but do we, as individuals, really choose what we eat? There are many reasons to doubt this.

Let us take a closer look at this: obesity has a direct relationship with eating; "not eating" will never lead to obesity. Health literature shows the main pathways to prevent or overcome obesity: give every individual access to education about healthy food and stimulate a healthy diet together with physical activity in those who are overweight. But there are several mediating influences, the most important ones being genetic predisposition, behavioral and psychological characteristics, parenting and education, and economic and social factors.

Let us first explore parenting and education. The best prediction of infant obesity seems to be the body mass index (BMI) of parents. Moreover, intrauterine life, infancy, and preschool years include critical periods that pro- gram the long-term regulation of energy balance. If parents use a pile of butter on every piece of bread their baby devours, the taste preferences and the weight of the baby will be influenced. However parents are also influenced by their own education, the food patterns they were exposed to, and so on. As a result, being overweight is often a "family characteristic." 6

Becoming obese also relates to genetic factors; a person can be a fast or a slow fat burner. Although the scientific community is still a long way from reaching a comprehensive picture, there are an increasing number of studies that deal with genetic variants as having a significant impact on obesity and other health-related problems. Although these studies underline the complex interactions between genetic and environmental factors, novel forms of treatment or interventions may result that could assist in improving the quality of life. 7

Like all behavior change, weight loss is difficult to accomplish. It depends on motivation and psychological characteristics of the person. Several treatment approaches try to overcome these problems. Those of Miller, Rolnick, Prochaska, and DiClementi are probably the best known. They emphasize that adapting a person's diet or changing to more physical activity is more than a matter of being "just willing"; it involves "stages of change," including a shift from "not recognizing there is a problem" to "active problem solving by looking for the 'best fit' solution." ${ }^{8}$ These stages of change are connected with personal characteristics of the individual. At the personal level, it might be that dealing with obesity is more difficult for some than for others.

Everyone lives in context. There is a shared interaction between society and the economy in determining the style of our lives. It is, of course, the 
individual who makes his or her own choices, but the context within which he or she can choose is not a matter of choice. This social and economic context is more than just a footnote in the debate on lifestyle; it is a crucial element. Obesity is especially a problem of contemporary society. Everywhere in city streets, you can drink Coke or eat burgers, an incentive that cannot be overestimated. Children and other vulnerable groups in society are sometimes "defenseless" in giving in to advertisements or the free availability of junk food. ${ }^{9}$ Since "bad" food is everywhere, many of us find it hard to resist. Therefore, among other factors, we eat more because food, especially unhealthy food, is always available. As Meridith Minkler points out: "Americans not only are bombarded with advertisements for high-fat, high-calorie foods but consistently are provided large servings of such foods when they eat at most restaurants and fast-food establishments." 10 The food industry persists in developing a grip on our food habits and tastes by using food supplements and so forth. These food habits are often unhealthy, because most food multinationals persist in distributing fatty and sweet foods. ${ }^{11}$

Also, many of us do very little physical activity and thus use up less energy than we used to in previous generations, while we should be doing more to counter the intake of more energy. This is not simply because we are weak or unwilling to practice sports or to undertake any physical activity. Various structural facts direct our behavior and lifestyle. Our jobs have evolved from physically intense to sedentary. During working hours, many of us do not have the opportunity to exercise. The way people commute between home and office or school has also changed dramatically in many Western countries. In Belgium, for instance, many children are brought to school by car, often because traffic is too dangerous (ironically, this is partially caused by the cars of parents driving their children to school). In addition, the environment often does not offer us many opportunities for physical activity: there is a lack of public parks, walking zones, and so forth.

The key point here is not that we are devoid of responsibility for our own choices. Of course, the individual is responsible, but the question is what makes us choose what we choose? Or to put it bluntly, are our food choices well-informed and deliberate choices and the result of mere individual lifestyle decisions? ${ }^{12}$ Besides differences in taste and the complex matter of how we develop taste, the question remains of whether the choice of what is on our plate is only our own. As Eli Feiring writes: "It is hard to identify any action that is not partly determined by circumstance understood as the social contexts in which the individual finds herself or her traits of character (included the ability to choose)."13

\section{Genealogy of Lifestyle}

Because lifestyle is not a neutral category to describe an objective reality, ${ }^{14}$ any altering of its meaning can have important consequences for the way we deal with the responsibility of the individual for his or her own life. The brief discussion of the example of obesity demonstrates that ethical considerations about lifestyle leave out many important arguments if they are limited to the narrow meaning of lifestyle as a matter of independent choice by a rational individual. This brings us to the next question: are there any other (forgotten) meanings of lifestyle around which we could broaden our horizon and allow us to tackle contemporary 
ethical (lifestyle) issues such as obesity from a wider point of view? And could this broadened horizon lead to the formulation of another type of health policy, one which is based on a different set of ethical premises?

As suggested earlier, we turn to Foucault's genealogical method to unravel the correlation of the shift of the meaning of "lifestyle" with the way we talk about individual choice and responsibility for our lives in bioethics. Although the meaning of the concept of lifestyle seems quite obvious at first, it is not. It appears to be used at least as a sociological category, an ethnographic generic concept, a target for marketers, a psychological notion, a diagnostic tool, an ethical idiom, and an object of medical attention.

\section{The Meaning of Lifestyle}

Although lifestyle has been a very popular concept in medical science for several decades now, our genealogical analysis of its meaning brings us back to the first half of the 20th century. In sociology, it is commonly understood that the spread of lifestyle in medical discourse originates in Wirtschaft und Gesellschaft [Economy and Society] by the sociologist Max Weber. Weber indeed wrote about lifestyle and considered it as realized primarily by the choices of an individual within one's social context, limited by the chances one is offered. To theorize the question of lifestyle, Weber developed three concepts: stylization of life [Stilisierung des Lebens] or lifestyle [Lebensstil]—both concepts actually mean the same (Weber varies only in the formulation of it), life conduct [Lebensführung], and life chances [Lebenschancen]. ${ }^{15}$

Although we do not underestimate the importance of Weber, there is another scientist of at least equal importance in the genealogical history of lifestyle. In the 1930s, the Austrian psychologist Alfred Adler talked about what he called a "style of life." ${ }^{16} \mathrm{He}$ conceived a style of life as an individual's personality, mental attitude, and uniqueness. Each individual, from early childhood onward, develops a style of life that is greatly influenced by the innate social interests of that person. As children grow up, they adopt a pattern of behavior and set their goals. A style of life in the Adlerian sense of the word is therefore to be understood quite literally: the personality style or attitude individuals have chosen and resort to for the rest of their lives, be it primarily unconsciously. ${ }^{17}$ By this, Adler means that the choice for a particular style of life is not a deliberate or conscious matter, but rather the result of an adaptation by the young child that is used later on to deal with various tasks in life.

In 1938, Walter Langdon-Brown dedicated the last section of his first chapter in Thus We Are Men to Adler's style of life, transforming this concept into a diagnostic tool applied to patients and how they cope with the difficulties of the real world and, as part of that, escape into fantasy as a sort of compensation. ${ }^{18}$ A style of life, he writes, is a retreat into fantasy whenever the real world is too confrontational. A sick person, for instance, might imagine he is well enough to have the energy or courage to keep going. For Langdon-Brown, medicine should cooperate with psychology if it wants to obtain a more far-reaching insight into the human mind. ${ }^{19}$

Despite its introduction in the first half of the 20th century, for a long time the concept of lifestyle was not really an issue, either in science or in society in general. It was not until the 1960s and 1970s that its meaning expanded. Since then, it not only functions as a general category used in several scientific 
contexts, from medical science to sociology and to cultural studies, but also as a synonym for the way we express ourselves. $^{20}$ In short, we are the style we choose. It is now common practice for advertisers to seduce us with the illusion that their products are especially made for us; the promise is that of a unique lifestyle.

In a way, "traditional" healthcare by and large adopted the idea of lifestyle conceived as a personal choice. ${ }^{21}$ The argument goes as follows: if we, as individuals, choose a lifestyle, then approaches in healthcare are justified in emphasizing the role of individual choice and responsibility and in devoting less attention for structural or

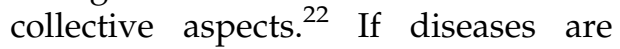
claimed to be the result of lifestyle choices and not of biological fate or social circumstances, this means they could have been avoided had the individual's style of living been different. In summary, if lifestyle was initially a symptom of disease, it ultimately became the cause of it.

Today, the concept of lifestyle "is applied to a wider and more general conception of styles of living." ${ }^{23}$ Mainstream healthcare discourse is about facilitating individuals to make their own (bioethical) choices. Although lifestyle is conceived as a determinant of disease (a cause), it is also a crucial element in the prevention of disease and thus a determinant of health. Lifestyle is something we can overcome either with pharmacological assistance in the form of so-called lifestyle drugs or nonpharmacologically, with intensive lifestyle changes supported by well-developed healthcare or through medical interventions.

\section{Discussion}

From our rudimentary genealogical analysis (see Figure 1), we can begin to understand the changing meanings of lifestyle. A first characteristic in this evolution is the shift from style of life as a largely unconscious process toward lifestyle as the deliberate choice of an individual. As Adler conceived it, style of life was a sort of semiconscious weapon that the individual used to cope with life and all of its challenging demands. As the concept of lifestyle was transformed into a broad concept used in several contexts, its meaning developed in the direction of the thoughtfully chosen and highly intentional expression of an isolated person: lifestyle as the result of the free choice of the individual subject. In medical discourse in general and discourses of public health in particular, we are all supposed to be fully responsible for our own lives (and lifestyles). And when it comes down to health insurance, individuals then bear the full financial responsibility for lifestyles of which they are not the sole authors. None of us, when trying to cope with the rising costs of medical insurance, can lower the cost of one's insurance policy by defending ourselves with the argument "Sorry for my sedentary lifestyle, but my neighborhood is too dangerous to walk through" or "Sorry for my behavior but my lifestyle drugs were too expensive."

More recently, lifestyle has been relocated somewhere between styles of living and living conditions. ${ }^{24}$ It is often defined as the combination of individual behavior and social circumstances as found, for instance, in Cockerham's definition of health lifestyles from 2005: "collective patterns of healthrelated behavior based on choices from options available to people according to their life chances." 25 Although the individual remains responsible for his or her own life, there is at least the important nuance that individuals participate in a social environment, that 


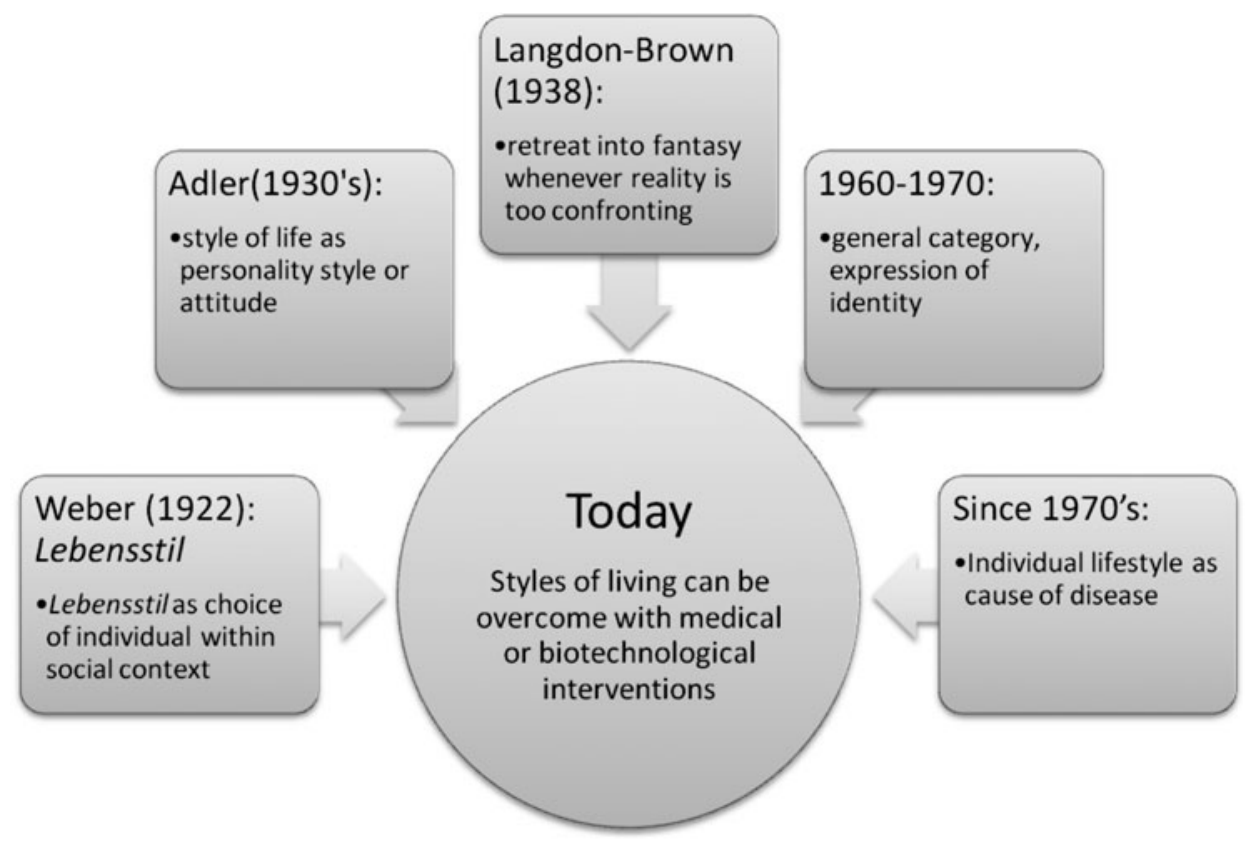

Figure 1. Genealogy of the meaning of lifestyle.

there are inequalities in living conditions, in opportunities, and in education, and that all of these aspects are significant for the question of lifestyle and/or responsibility in bioethics and healthcare in general.

Crucial points in today's discussion of lifestyle are whether or not we really choose (the style of) our life and who is responsible for it. This discussion has the most immediate consequences for the way we deal with healthcare issues today: liver transplants, lung cancer caused by smoking, treatment of dental caries, and so forth. If all of these issues and many others are analyzed as lifestyle matters, a different concept of lifestyle can lead to quite dissimilar ethical or political decisions on healthcare. To argue this, let us return to the example we started out with, that of obesity.

If we suppose obesity to be a matter of lifestyle, how do we deal with it? Today, the commonsense meaning of lifestyle considers obesity to be caused by the behavior of individuals. Assuming we agree on this concept of lifestyle as an autonomous, conscious choice of an individual, it would make obese patients responsible for their unhealthy habits; but even then we would still not be able to answer unambiguously the question of whether we should treat such people differently. As Holm suggests, what about the non-obese-related instances of negative health effect of personal choice: should we then not treat them in the same way? ${ }^{26}$ As long as we are unable (or unwilling) to do this, is it not rational to conclude that many parties are responsible in the case of obesity and that it would indeed be perverse to hold only one party responsible for it, as an inevitable consequence of persistently individualistic interpretations of lifestyle?

Additionally, as of today, we do not know for sure what the causes are of 
obesity and how they interact: there is only minor evidence concerning how exactly obesity relates to more energy intake or only less physical activity, and in Europe there is even no agreement on what is unhealthy food. ${ }^{27}$ Why then act as if we are certain about the problem of obesity, its causes, and its consequences? Is it not tendentious to allocate a priori the responsibility for something that is not even well defined? It is what Neil McLaughlin in his article "Stop Blaming the Patient" calls "our ignorance about health":

The public is battered by contradictory studies on what's good or bad for you. Did you think you should lose some pounds? A recent study suggested that being slightly overweight can extend your life. Did your doctor tell you to lower your "bad" cholesterol? A new and disappointing examination of a cholesterol-lowering drug is making a lot of researchers think that might not be a good approach. (So we have wasted billions on such drugs?) Some physicians used to say drinking alcohol was bad; now a little may be good. Butter was bad; now we're told trans fats are as bad or worse. Dermatologists have long preached that you should avoid the sun lest you get skin cancer; now some researchers think indoor living and sunscreenslathering have caused widespread vitamin $\mathrm{D}$ deficiencies, leading to more breast and prostate cancer and high blood pressure, among other ills. Just last week, a new study contradicted a study from the previous week that said aggressive lowering of blood sugar could be harmful to diabetics. ${ }^{28}$

If we conceive of lifestyle as a deliberate and rational choice of an independent individual and consequently view obesity as the result of this, then the question remains of why so many people are acting in the same way at the same time and place. Is this really because all of a sudden, one by one, half of the Western population quite independently chose to eat and drink too much and/or to no longer have any physical activity? The obviously rhetorical nature of our question indicates that the answer "no" can be taken as a given, and yet the point is nevertheless of crucial importance for current bioethical debate.

Conversely, we do not opt for the former "Marxist" thesis by saying that the "system" is responsible for everything. It is not that our choices are determined solely by social circumstances; it is not because our particular social context offers us fewer opportunities for physical activity that we are destined to live our life as obese. Inasmuch as we should stop "blaming the patient" because of his risk behavior, we cannot simply shift the responsibility of the individual's lifestyle to society.

Instead, we suggest the counterintuitive thesis: there are aspects of our behavior for which no one is responsible. By this we mean that much of our choices are developed as a strategy for living our lives or-analogously to what Carl Elliott writes about values in his A Philosophical Disease. Bioethics, Culture and Identity - "the result of cultural factors beyond our reach." ${ }^{29}$ Why, for instance, do most people become anxious when we talk about human genetic manipulation? As long as lifestyle is considered to be based solely on independent, conscious, and deliberate choices, be they taken individually or collectively, we will never solve the question of why people are "choosing" one thing or refusing another.

The discussion concerning who is responsible for our lifestyle is perhaps the wrong, or at least an unnecessary, debate. It is time to reframe the discussion. By putting forward the thesis that no one is responsible for certain aspects of our behavior, we contradictorily 
reassess the question of responsibility. Although we make our own choices, lifestyle is far more than the personal expression of who we are and more than what society says we should be: sometimes it is a survival strategy, a way to deal with stress and anxieties-in short, a method of living your life. It is a matter of chances and opportunities, education, and environment. This is also a question of why some people succeed in managing certain opportunities whereas others do not. Above all, lifestyle is never simply the result of a conscious and rational choice; it is also the result of personal habits and desires, a great many of which play their role at an unintentional level. And, finally, it is partly the result of cultural or societal habits, patterns, or evolutions far beyond our individual reach.

What can genealogical analysis of the shift of the meaning of lifestyle offer as added value to this debate? Our discussion has been fairly general, because of the limits imposed by a journal publication. Despite this, our genealogical approach at least puts on the agenda the idea that if we conceive of lifestyle as involving far more than the result of a deliberate process, we change our outlook on "hot" issues in contemporary bioethics and healthcare. Because today we are faced with increasing biomedical opportunities and therefore are unable to move toward the possibility that we are the life (-style) that we want to be, to reflect thoroughly on the main options for bioethics in the future is not an idle pastime. Such reflection is urgent and of major importance, because significant choices have to be made. ${ }^{30}$

If, subsequently, we plead for an enlarged concept of lifestyle as Adler and others once suggested, then maybe we will succeed in understanding why obesity involves far more than a question of individual lifestyle and responsibility.

\section{Conclusion}

To reframe current debates on obesity and other topics in health ethics, it is interesting to remind ourselves of Adler's meaning of lifestyle, as a strategy to deal with life in general. Since we have evolved from the notion of a "style of life" as a partially unconscious, unintentional matter toward the notion of "lifestyle" as something for which a person is fully responsible, in particular when it comes down to "risk behavior," a reminder of the original connotations can help us reframe current bioethical dilemmas. We want to plead in favor of a broader framework for handling the question of lifestyle in general and that of obesity in particular. By narrowing the field of intervention in advance, the fundamental options are too easily taken for granted. The genealogy of lifestyle has made it clear that there are alternatives to limiting our concept of lifestyle to the results of the conscious choices made by an individual.

\section{Notes}

1. Caplan A, Elliott C. Is it ethical to use enhancement technologies to make us better than well? PLoS Medicine 2004;1(3):e52.

2. Cosner L Jr. Lifestyle is an issue. Modern Healthcare 2008;38(13):21.

3. Meadmore D, Hatcher C, McWilliam E. Getting tense about genealogy. International Journal of Qualitative Studies in Education 2000;13:463-76; Foucault M, Burchell G. Security, territory, population: Lectures at the Collège de France, 1977-1978. Basingstoke, UK: Palgrave Macmillan; 2007; Foucault M, Burchell G, Gordon C, Miller P. The Foucault effect. Studies in governmentality with two lectures by and an interview with Michel Foucault. Hertfordshire: Harvester Wheatsheaf; 1991.

4. See note 2, Cosner 2008:21.

5. Giordano S. Should we force the obese to diet? Journal of Medical Ethics 2008;34(5):319.

6. Olstad DL, McCargar L. Prevention of overweight and obesity in children under the age of 6 years. Applied Physiology Nutrition and Metabolism 2009;34(4):551-70. 
7. Andreasen $\mathrm{CH}$, Andersen G. Geneenvironment interactions and obesityFurther aspects of genomewide association studies. Nutrition 2009;25(10):998-1003.

8. Prochaska JO, Diclemente CC, Norcross JC. In search of how people changeApplications to addictive behaviors. American Psychologist 1992;47(9):1102-14; Miller WR, Rollnick S. Motivational Interviewing: Preparing People to Change Addictive Behavior. New York: Guilford Press; 2002.

9. Matthews AE. Children and obesity: A panEuropean project examining the role of food marketing. European Journal of Public Health 2008;18(1):7-12.

10. Minkler M. Personal responsibility for health? A review of the arguments and the evidence at century's end. Health Education $\mathcal{E}$ Behavior 1999;26(1):121-41.

11. Nestle M. Food Politics. How the Food Industry Influences Nutrition and Health. Berkeley: University of California Press; 2002.

12. Holm S. Obesity interventions and ethics. Obesity Reviews 2007;8(s1):207-10; Holm S. Parental responsibility and obesity in children. Public Health Ethics 2008;1(1):21-9.

13. Feiring E. Lifestyle, responsibility and justice. Journal of Medical Ethics 2008;34(1):33-6.

14. Hansen E, Easthope G. Lifestyle in Medicine. London: Routledge; 2007.

15. Cockerham WC, Rütten A, Abel T. Conceptualizing contemporary health lifestyles: Moving beyond Weber. The Sociological Quarterly 1997; 38(2):321-42.

16. Adler A, Ansbacher HL, Ansbacher RR. The individual psychology of Alfred Adler: A systematic presentation in selections from his writings. Adler A, ed., annotated by Ansbacher HK, Ansbacher RR. New York: Harper and Row; 1964.

17. Seidmann P. Life goal and lifestyle-Basics of teleoanalysis according to Adler. Schweizerische
Zeitschrift Fur Psychologie Und Ihre Andwendungen 1981;40(2):171; Petti S. Lifestyle risk factors for oral cancer. Oral Oncology 2009;45(4-5): 340-50.

18. Langdon-Brown W. Thus We Are Men. London: Kegan Paul, Trench, Trubner; 1938.

19. Keynes M. Sir Walter Langdon-Brown (18701946). Journal of Medical Biography 2008; 16(1):3-6.

20. Bell D, Hollows J. Towards a history of lifestyle. In: Bell D, Hollows J, eds. Historicizing Lifestyle. Hampshire: Ashgate; 2006:1-20.

21. Pearce N. Traditional epidemiology, modern epidemiology, and public health. American Journal of Public Health 1996;86(5):678-83; Backett KC, Davison C. Lifecourse and lifestyle: The social and cultural location of health behaviours. Social Science and Medicine 1995;40(5):629-38.

22. Cockerham WC. Health lifestyle theory and the convergence of agency and structure. Journal of Health and Social Behavior 2005; 46(1):51-67; Katherine LF, Ellen C, Louise P. A theoretical proposal for the relationship between context and disease. Sociology of Health \& Illness 2001;23(6):776-97.

23. See note 15, Hansen, Easthope 2007.

24. Charbonneau J, Gauthier M. Introduction: Culture and lifestyle. Loisir et Société/Society and Leisure 2001;24(2):353-6.

25. See note 22, Cockerham 2005.

26. See note 12, Holm 2007.

27. See note 9, Matthews 2008.

28. McLaughlin N. Stop blaming the patient. Modern Healthcare 200;38(7):1.

29. Elliott C. A Philosophical Disease: Bioethics, Culture and Identity. London: Routledge; 1999.

30. Ornish D. Intensive lifestyle changes and health reform. The Lancet Oncology 2009; 10(7):638-9; Elliott C. Better than Well: American Medicine Meets the American Dream. New York: Norton; 2003. 